\title{
Performance of Fly Ash as Replacement for Non-Renewable Constituent in Asphaltic Concrete for Road Development
}

\author{
Ezemenike Chukwuka $^{1} \bowtie$, Oyedepo Olugbenga ${ }^{1}$, Aderinlewo Olufikayo ${ }^{1}$ and Oladele O. Isiaka ${ }^{2}$ \\ ${ }^{1}$ Department of Civil Engineering, Federal University of Technology, P.M.B, 704, Akure, Ondo State, Nigeria \\ ${ }^{2}$ Department of Metallurgical Materials Engineering, Federal University of Technology, P.M.B, 704, Akure, Ondo State, Nigeria \\ ${ }^{\star}$ Corresponding author's Email: ezestan2013@gmail.com; (DORCID: 0000-0001-5644-0812
}

\begin{abstract}
The non-renewable constituent used in asphalt concrete consumed large amount of materials resulting an increase in the price of asphalt mixture and consequently the cost of road development. On the other hand, huge industrial waste being generated daily from human activities causes environmental degradations. Thus, the study evaluates the performance of fly ash (FA) in asphalt concrete development targeted for road application. The aggregate, bitumen, and fly ash were characterized before being used. The stone dust in asphalt mixture was replaced with FA in predetermined proportions of $2,4,6$, and $8 \%$ to produce a cylindrical specimen of asphalt mixture concrete. Marshal stability test, flow test, X-ray diffraction (XRD), X-ray Fluorescence (XRF) and Scanning Electron Microscope (SEM) was conducted on the composite samples. From the results, stability values of 7.39, 7.70, 7.90 and $8.22 \mathrm{KN}$ was obtained at 2, 4, 6 and $8 \%$ replacements, respectively. Hence, the optimum value of $8.22 \mathrm{KN}$ obtained from $8 \%$ partial replacement with FA is adequate for heavy traffic while other partial replacement from 2$6 \%$ with stability within the range of 7.39-7.90 KN is suitable for medium traffic in accordance with the criteria for the marshal mix design method provided by Asphalt institute (1997). Corresponding values of 3.7, 3.5, 3.3 and 3.0 $\mathrm{mm}$ was obtained for the flow. The flow, air void, void in mineral aggregates and void filled with bitumen results all satisfied Nigeria general specification for road and bridges (1997). Therefore, fly ash can be used as partial replacement in asphaltic concrete to enhance the performance of the mix with a reduced cost for pavement construction.
\end{abstract}

Keywords: Asphalt Concrete, Fly Ash, Road, Stability, Transportation

\section{INTRODUCTION}

The asphalt concrete is a composite mixture of aggregates, binder and filler mixed at specified percentages. One of the major concerns of highway engineers on the design of asphalt concrete mixture is the type and quantity of stone dust utilized that possibly influences the mechanical properties of the blend (Hossain et al., 2018). Several researchers have carried out investigations on the characteristics of filler materials; especially fillers passing $0.0075 \mathrm{~mm}$ sieve size to assess the impact on the mechanical properties of bituminous paving mix in terms of void filling, consistency, mix strength and marshal stability (Hossain et al., 2018).

The Fly ash (FA) is the ruminants obtained from burning of coal and wastes from the thermal power. It consists of aluminosilicate glass, mullite, and quartz, which are gathered by electrostatic separators of gaseous products from coal ignition (Vučinić et al., 2003). Accordingly, Kumar and Kumar Chhotu (2014) describe it as a heterogeneous material that comprises of significant chemical compositions such as silicon oxide, calcium oxide, aluminium oxide, magnesium oxide, iron oxide, potassium oxide and oxygen. Fly ash is sub-divided into two classes which are class $\mathrm{F}$ and class $\mathrm{C}$. The fly ash generated from the combustion of anthracite bituminous coal yield class F fly ash, while burning of lignite or subasphalt coal make up fly ash class $\mathrm{C}$. The Class $\mathrm{C}$ fly ash consists of $20 \%$ lime $(\mathrm{CaO})$ and has self-cementing and pozzolanic characteristics. Though, Fly Ash Class F consists of $10 \%$ lime $(\mathrm{CaO})$ and has pozzolanic properties that required a cementing performer, such as quicklime, hydrated lime or Portland cement

Fly ash has effectively being used as filler (stone dust) in asphalt paving blend and it had the benefit of increasing the resistance bitumen blends resistance. Fly ash in bituminous mixture industry reduces pavement performance deteriorations causes as result of exposure to vehicular stress, weather and atmospheric changes which widely generated favourable results as compared to 
polymer modified asphaltic binder (Sobolev et al., 2014). A new report showed that consolidating fly ash enhances rheological and mechanical characteristic, diminishing prices and horrible ecosystem impact (Tapkin, 2008). The elastic properties of 40/50 penetration grade bitumen were to increase by utilizing fly ash (Sarsam and Lamy, 2015). Their study also shows that 60-70 penetration grade bitumen consisting of fly ash has a comparative increase to permanent deformation. Adil and Saadoon (2019) studied the use of cement production waste to enhances the properties of hot mix asphalt concrete, they considered cement kiln dust as non-conventional filler and the result indicated that cement kiln improved fatigue life, rutting, mix cohesion and marshal stability of asphaltic concrete mixture and research done by Sharma et al. (2010) on the performance characterization of bituminous concrete with industrial waste as a filler in which they used granite, marble dust and fly ash as non-conventional filler and the results showed that fly ash, granite and marble dust have good ability for their use as filler in asphaltic concrete mixture.

Worldwide, industrial waste from thermal combustion of coal is been used for soil and asphalt stability, concrete production and as raw material for cement and embankment works among others (Hashimoto and Torii, 2013). According to Malhotra (2002), annual global production of fly ash is closely 500 million tonnes, but only approximately $20 \%$ is being utilized by the concrete industry. The united states of American alone generates up to 131 million tons of fly ash every year (Johnson, 2009). In Nigeria, Fly ash is generated as waste from a thermal power station in six unique deposits from Odagba in Kogi State, Owukpa in Benue State, Ezimo, Amansi Modo, Inyi and Oji River town in Enugu state (Ademola and Onyema, 2014). Globally, $65 \%$ of fly ash generated is discarded off in landfill and pond ash (EPA, 2005). The USEPA (United Stated Environmental Protection Authority) adduced that if 42 million tons of FA generated was reused, approximately 34 million cube of land fill space will not be demanded. However, highway engineers can use fly as a substitute for filler to enhance the performance of the asphalt concrete for road construction and rehabilitation. Thus, the use of FA to partially or wholly replace filler in asphalt concrete will not only reduce the degradation of the environment due to the waste generated, but will also reduce the quantity of non-renewable materials being used in asphalt concrete which will reduce the cost of road construction. Most of the previous researches carried out using fly ash as partial replacement for filler in asphalt concrete did not examined the influence of the microstructure on the composite samples. Hence, this study seeks to carry out microstructural examination of the composite samples through the use of SEM on samples subjected to nano test and the impact of axle load.

\section{MATERIALS AND METHODS}

\section{Materials used}

The aggregate used was procured from RCC and JCC quarry located along Akure-Owo Express Road in Oba-Ile, Akure North local Government Area, Ondo state, Nigeria. Fly ash was gotten from burning chambers around vicinity of the thermal station in Oji river town, Enugu state, Nigeria while Bitumen was acquired from K.K. Hassan Construction Company in Akure, Nigeria with penetration grade of 60/70.

\section{Methods}

Fly ash was exposed to the sunlight for two day to eliminate some of the moisture content before carrying out Hydrometer test which was carried out in accordance with American Society for Testing and Material (ASTM D7928-17). Fly Ash was used as partial replacement to stone dust in varying proportions of $2,4,6$, and $8 \%$.

\section{Physical characterization of aggregates}

The test performed on the aggregates are flakiness and elongation test (BS 812: Part 105:1: 1985), aggregate impact values test (AIV) (BS 812-112:1990), moisture content (BS 812-109:1990), specific gravity test (ASTM C 127-12), aggregate crushing values and (ASTM C131/CI3I), respectively.

\section{Physical characterization of bitumen}

The essential physical test on the bitumen performed to determine its suitability are Flash and fire point test (ASTM D92-16b), Softening point (ASTMD36/D36M=14el), Viscosity Test (ASTM D2170/D2170M-10), Water in bitumen test Dean and Stark Method (ASTM 95-05), Ductility test (ASTM D11317) and penetration test (ASTM D5/D5M-13), respectively.

\section{Physical characterization of fly ash}

The physical tests carried out to characterize fly ash material are Specific gravity (ASTM C127-12), Moisture content test (BS 812-109:1990) and Hydrometer (ASTM D7928-17) 
Chemical characterization of fly ash

X-ray Diffraction (XRD) (ASTM D113-17) and X-ray fluorescence (XRF) (ASTM D3906-19) were carried on the fly ash to check chemical properties and other elemental compositions.

Marshall Bituminous mix design (ASTM D 692706) and composites development

Aggregates of about $1200 \mathrm{~g}$ comprising distinct aggregate fraction with sizes of $8.00,5.00$ and $2.36 \mathrm{~mm}$ and, filler (stone dust) of $4.76 \mu \mathrm{m}$ were pre-heated within the range of $160-178^{\circ} \mathrm{C}$. The selected bitumen content of $5 \%$ was melted to $150{ }^{\circ} \mathrm{C}$. The aggregates and bitumen were mixed together inside the steel bowl. The mix was completely blended at mixing temperature of about 185 ${ }^{\circ} \mathrm{C}$. The mixture was compacted in fore-heat marshal mould by applying 50 blows on each face of the sample. Ten samples were set up by replacing filler (stone dust) with fly ash at different proportion of 2, 4, 6 and $8 \%$ were produced. The marshal stability and flow were carried out on the samples While Void in mineral aggregate (VMA), Air void (AV), bulk density (BD) and Void filled with bitumen (VFB) was determined.

Microstructural image of fly ash modified asphalt

The SEM of the fly ash modified asphalt fracture surface was carried out using EVO MA 15, Carl zeiss SMT to analyse the microstructure of asphalt mixture. The samples were gold sputtered to improve electrical conductivity.

\section{RESULTS AND DISCUSSION}

Table 1 present the values obtained for the moisture content, aggregate impact (AIV), aggregate crushing (ACV), specific gravity, flashiness and elongation as; $0.65 \%, 22.20 \%, 30.18 \%, 3.0 \mathrm{~g}$ and 20.64 , respectively. From the results, it was observed that the aggregates conformed to relevant code recommendations which mean that the aggregates are tough, dense and can stand the test of both serviceability and durability requirement. Thus, they are suitable for the production of wearing course of asphalt concrete according to Nigeria General Specifications for Road and Bridges (1997).

Table 2 present the results of the penetration, softening point, flash point, fire point, ductility, viscosity and water-in-bitumen as; $62 \mathrm{~mm}, 46{ }^{\circ} \mathrm{C}, 207^{\circ} \mathrm{C}, 252$ ${ }^{\circ} \mathrm{C}, 148 \mathrm{~cm}, 129.4 \mathrm{sec}$ and $3.4 \%$, respectively. All these values conformed to the range specified in Nigeria General Specifications for Road and Bridges (1997).

Table 3 present the specific gravity and moisture content of fly ash as $2.305 \mathrm{~g}$ and $1.613 \%$, respectively. The values obtained have similarity with conventional filler (stone dust) and all were within the allowable limit of Nigeria General Specification for Road and Bridges (1997).

The results of hydrometer and particle size analysis were as shown in Figure 1. The analysis of hydrometer reveals that the sizes of gradation for the fly ash were from $0.001 \mu \mathrm{mm}$ to $0.01 \mu \mathrm{mm}$, thus, it is suitable to be used as filler in asphalt concrete.

Table 1. Physical properties of aggregate

\begin{tabular}{lccc}
\hline Test Conducted & Code Used & Code Limit & Test result \\
\hline Moisture Content (\%) & (BS 812-109:1990) & Max 5\% & $0.65 \%$ \\
Aggregate Impact value (\%) & (BS 812-112:1990) & $20-30 \%$ & $22.20 \%$ \\
Specific gravity & (ASTMC 127-12) & $2.5-3.0 \mathrm{~g}$ & $3.0 \mathrm{~g}$ \\
Aggregate Crushing value (\%) & (ASTMC 131/C131) & $27-35 \%$ & $30.18 \%$ \\
Flakiness and Elongation Index test (\%) & (BS 812:105:1:1985) & Max 30 & $20.64 \%$ \\
\hline
\end{tabular}

Table 2. Physical properties of bitumen

\begin{tabular}{lccc}
\hline Test Conducted & Code Used & Code Limit & Test result \\
\hline Penetration, mm & ASTM D5-95 & $60-70$ & $62 \mathrm{~mm}$ \\
Softening Point, ${ }^{\circ} \mathrm{C}$ & ASTM D36-76 & Min 45 & $46^{\circ} \mathrm{C}$ \\
Flash point, ${ }^{\circ} \mathrm{C}$ & ASTM D92-90 & Min 200 & $207{ }^{\circ} \mathrm{C}$ \\
Fire Point, ${ }^{\circ} \mathrm{C}$ & ASTM D92-90 & Min 240 & $252^{\circ} \mathrm{C}$ \\
Ductility, cm & ASTM D92-90 & Min 75 & $148 \mathrm{~cm}$ \\
Viscosity, sec & ASTM D92-90 & - & $129.4 \mathrm{sec}$ \\
Water-in-Bitumen & ASTM D95 & Max 5\% & $3.4 \%$ \\
\hline
\end{tabular}

Table 3. Physical properties of fly ash

\begin{tabular}{lccc}
\hline Test Conducted & Code Used & Code Specification & Result Obtained \\
\hline Specific gravity & (ASTM C127-12) & $2-2.5 \mathrm{~g}$ & $2.305 \mathrm{~g}$ \\
Moisture Content & (BS 812-109:1990) & Max 5\% & $1.613 \%$ \\
\hline
\end{tabular}




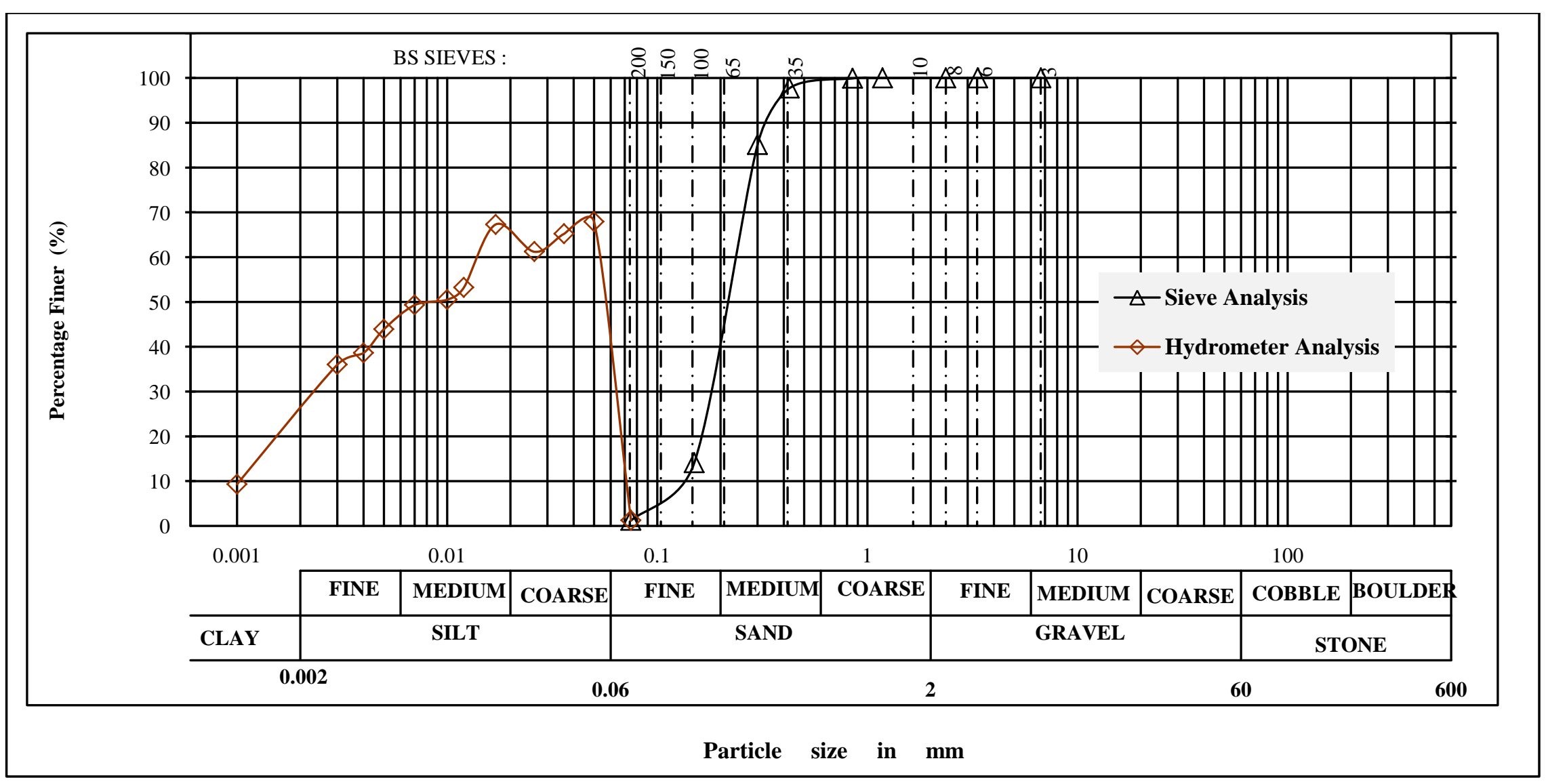

Figure 1. Particle Size Distribution Curve and Hydrometer. 


\section{Chemical characterization of the fly ash}

The results of fly ash XRD and XRF analysis were as shown in Figure 2 and Table 4, respectively. The diffractogram XRD comply with that of a glassy amorphous structure similar to the fly ash XRD diffractogram reported by Ismail et al. (2007). Fly ash has been described to be constituted of mainly silica, alumina and iron oxide (Ismail et al., 2007). The major peaks identified as the major phases present in the fly ash are quartz with traces of mica and calcite. The mica phase could be a combination of any of these polymorphs Lepidolite $\mathrm{K}(\mathrm{Li}, \mathrm{Al})_{3}\left(\mathrm{AlSi}_{3} \mathrm{O}_{10}\right)(\mathrm{O}, \mathrm{OH}, \mathrm{F})_{2}$, biotite $\mathrm{K}(\mathrm{Mg}$, $\mathrm{Fe})_{3}(\mathrm{AlSi} 3 \mathrm{O} 10) \quad(\mathrm{OH})_{2} ; \quad$ phlogopite $\mathrm{KMg}_{3}\left(\mathrm{AlSi}_{3} \mathrm{O}_{10}\right)$ $(\mathrm{OH})_{2}$; muscovite $\mathrm{KAl}_{2}\left(\mathrm{AlSi}_{3} \mathrm{O}_{10}\right)(\mathrm{OH})_{2}$. The mineralogical composition of the fly ash revealed by Ismail et al. (2007) was quartz, mullite and cristobalite. In all these phases, fly ash could be seen as a mixture of silica and alumina with traces of other elements. Hence, the fly ash used for this work complies with the mineralogical and compositional requirements for fly ash. The elemental composition result obtained from XRF analysis was presented in Table 4 from where it was also revealed that fly ash composed about $60 \%$ silica. The chemical composition was noticed to comply with the chemical composition of fly ash from various sources earlier reported (Ismail et al., 2007; Goodarzi, 2006).

\section{The Bituminous marshal result}

Table 5 shown the bituminous marshal results utilizing fly ash as partial replacement to filler (stone dust) in asphalt concrete while the summary of the criteria for bituminous marshal mix design method utilized is indicated in Table 6 .

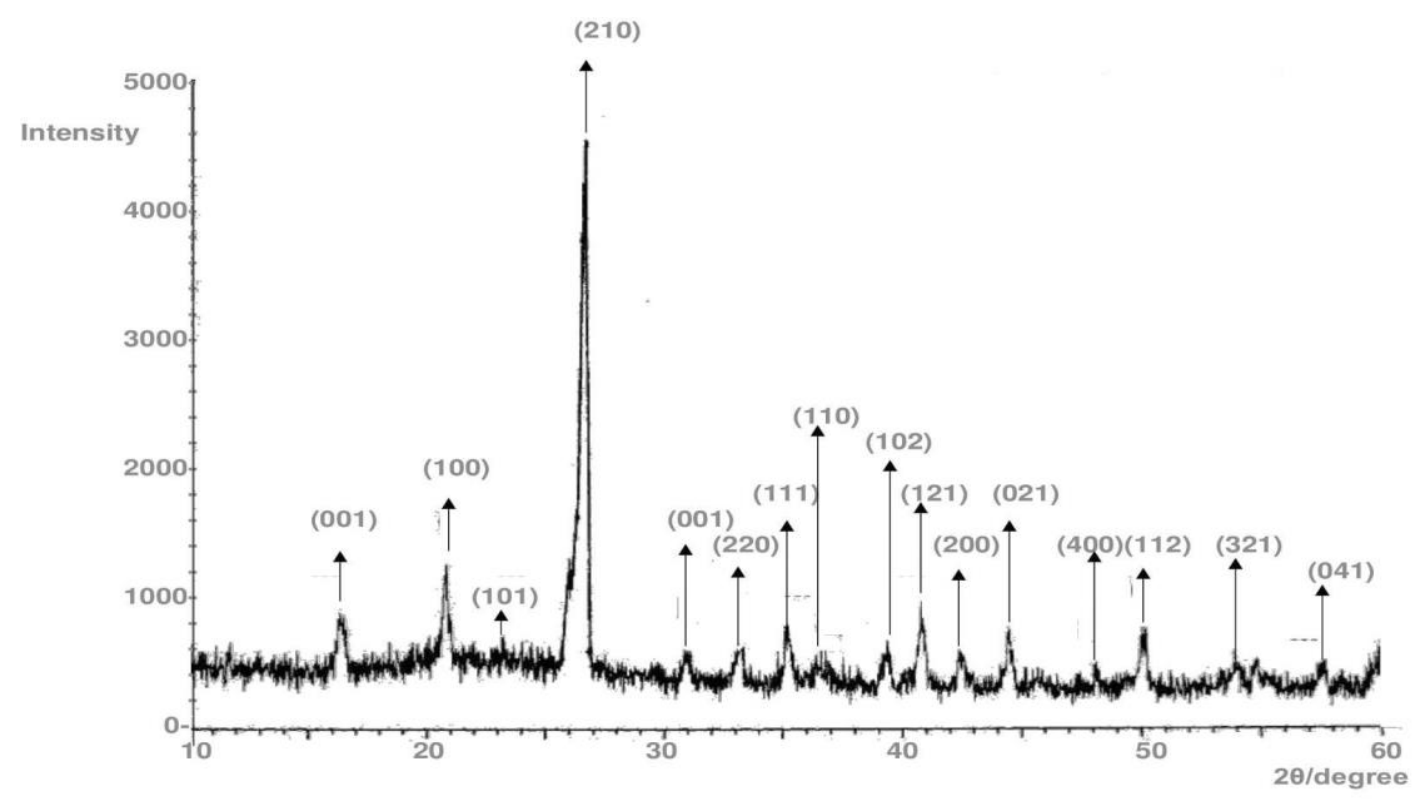

Figure 2: Fly Ash X-ray diffraction

Table 4. The XRF Analysis of Elemental Composition

\begin{tabular}{|c|c|c|}
\hline $\mathbf{S} / \mathbf{N}$ & Parameters & $\%$ Composition \\
\hline 1 & $\mathrm{MnO}$ & 0.05 \\
\hline 2 & $\mathrm{~K}_{2} \mathrm{O}$ & 1.73 \\
\hline 3 & $\mathrm{Fe}_{2} \mathrm{O}_{3}$ & 3.44 \\
\hline 4 & $\mathrm{SiO}_{2}$ & 60.32 \\
\hline 5 & $\mathrm{CaO}$ & 2.35 \\
\hline 6 & $\mathrm{Na}_{2} \mathrm{O}$ & 0.58 \\
\hline 7 & $\mathrm{Al}_{2} \mathrm{O}_{3}$ & 25.29 \\
\hline 8 & $\mathrm{MgO}$ & 0.77 \\
\hline 9 & $\mathrm{SO}_{3}$ & 3.02 \\
\hline 10 & $\mathrm{TiO}_{2}$ & 2.74 \\
\hline 11 & $\mathrm{~Pb}_{2} \mathrm{O}_{5}$ & 0.02 \\
\hline 12 & Loss of Ignition & 1.32 \\
\hline
\end{tabular}


Table 5. The Marshal Stability of Fly ash Modified asphalt concrete

\begin{tabular}{lccccccc}
\hline S/N & Proportion (\%) & bulk density & AV & VMA & VFB & Stability & Flow \\
\hline 1 & 0 & 2.467 & 4.18 & 21.70 & 80.73 & 7.45 & 3.8 \\
2 & 2 & 2.464 & 4.30 & 21.64 & 80.99 & 7.39 & 3.7 \\
3 & 4 & 2.460 & 4.47 & 21.61 & 81.17 & 7.70 & 3.5 \\
4 & 6 & 2.453 & 4.74 & 21.55 & 81.42 & 7.90 & 3.3 \\
5 & 8 & 2.449 & 4.90 & 21.42 & 82.09 & 8.22 & 3.0 \\
\hline
\end{tabular}

$\mathrm{AV}=$ Air void $; \mathrm{VMA}=$ Void in mineral aggregate; $\mathrm{VFB}=$ Void filled with bitumen.

Table 6. Typical Bituminous Marshall Design Criteria

\begin{tabular}{l|c|c|c|c|c|c}
\hline \multirow{2}{*}{ Mix Specification } & \multicolumn{3}{|c|}{$\begin{array}{c}\text { Heavy traffic } \\
\text { greater than 10 } \\
\text { ESALS) }\end{array}$} & \multicolumn{2}{|c|}{$\begin{array}{c}\text { Light traffic (less than } \\
\mathbf{1 0}^{\mathbf{4}} \text { ESAL) }\end{array}$} & $\begin{array}{c}\text { Medium Traffic (10 } \\
\mathbf{1 0}^{\mathbf{6}} \text { ESAL) }\end{array}$ \\
\cline { 2 - 6 } & Min & Max & Min & Max & Min & Max \\
\hline Stability (minimum) & $6672 \mathrm{~N}$ & - & $2224 \mathrm{~N}$ & - & 3336 & - \\
Flow (0.25mm) & 8 & 16 & 8 & 20 & 18 & - \\
Air voids (\%) & 3 & 5 & 3 & 5 & 3 & 5 \\
Compaction (50 blows each side of specimen) & 35 & - & 50 & - & 75 & - \\
\hline
\end{tabular}

Note: ESAL is the Equivalent Single Axle Load; Source: Asphalt Institute (1997).

\section{The stability result of fly ash modified asphalt concrete}

The stability results of fly ash are indicated in Figure 3 where it was observed that there was an increment from 0 to $8 \%$. This could be a result of fly ash that is acting as filler which filled the void in the asphalt mixture and make it stiffer and tough as the percentage of fly ash increases. The high stiffness of asphalt blend implies great resistance to traffic loading. The result also showed that the percentage of $0,2,4$, and $6 \%$ falls within minimum specified value for Medium traffic and $8 \%$ which is optimum value $(8.22 \mathrm{KN})$ falls within minimum specified value for heavy traffic as shown in Table 6 . It can be deduced from result that marshal stability values satisfied the specification given by Asphalt institute (1997).

\footnotetext{
The flow result of fly ash modified asphalt concrete

The result of flow is as shown in Figure 4 where it was observed that there was a drop from 2 to $8 \%$. The low flow values may indicate a mix with higher than normal voids and insufficient asphalt for durability and could result in premature cracking due to mixture brittleness during the life of the pavement. The flow values conformed to Nigeria general specification for Road and Bridge (1997) which stated that maximum of $4 \mathrm{~mm}$ to minimum of $2 \mathrm{~mm}$ is the acceptable range for wearing course in production of asphalt concrete
}

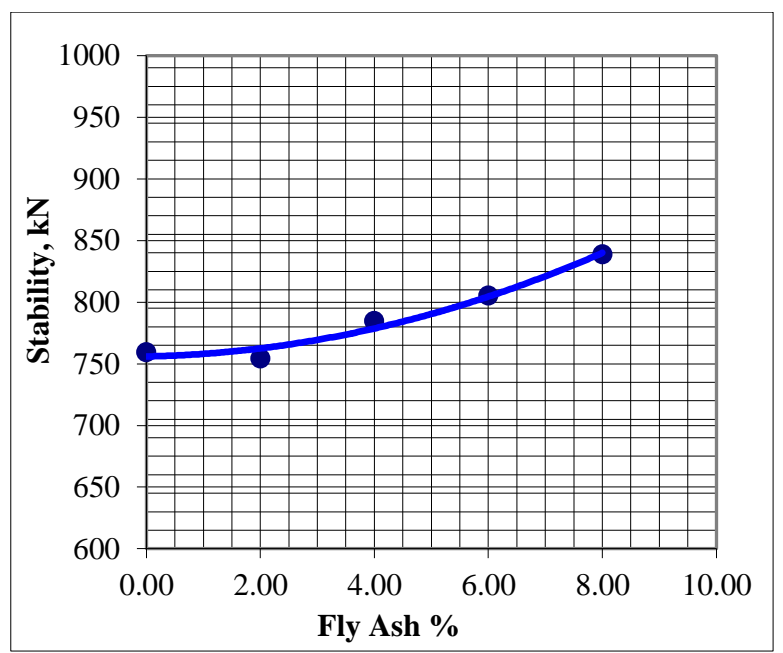

Figure 3. Stability result of FA

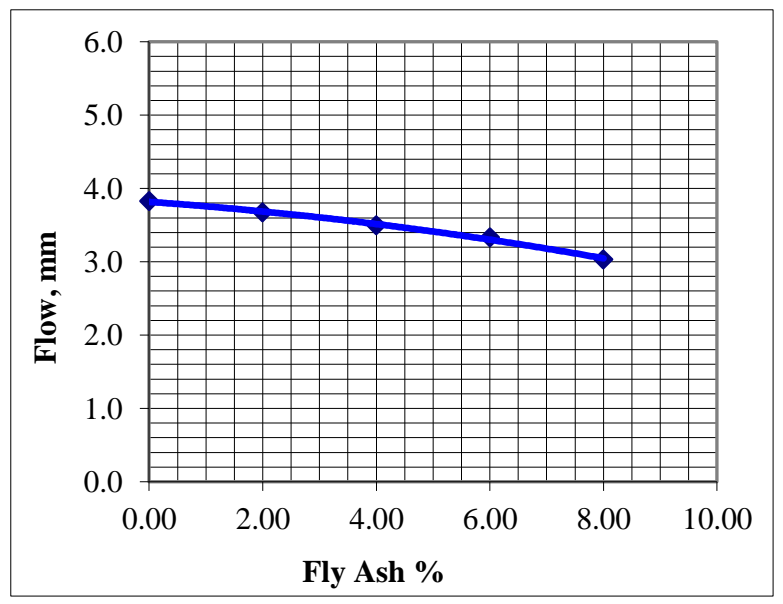

Figure 4. Flow result of FA 
The Bulk density result of fly ash modified asphalt concrete

The variations of bulk density result are shown in Figure 5. From the result, there was a constant decrease in bulk density from 2 to $8 \%$ fly ash. The decrease was as a result of the unit weight of stone dust being replaced that is greater than unit weight of fly ash.

The Air void result of fly ash modified asphalt concrete

Figure 6 revealed the result of Air void from where it was noticed that there is constant increase in Air void as the fly ash content increases up to $8 \%$. The Air void values obtained are suitable for light, medium and heavy traffic when compared with the Marshall Design criteria in Table 5.

The void in mineral aggregate for fly ash modified asphalt concrete

The result of VMA was presented in Figure 7 where there was an increase from 0 to $8 \%$. The void in mineral aggregates values all lie within the permissible limit specified by Nigeria general specification for Road and Bridges (1997).

The Void filled with Bitumen result for fly ash modified asphalt concrete

The Figure 8 indicated values of Void filled with Bitumen; from the result, there was a decrease from $0 \%$ to $8 \%$. The values obtained falls within the allowable limit provided by Nigeria general specification for Road and Bridges (1997).

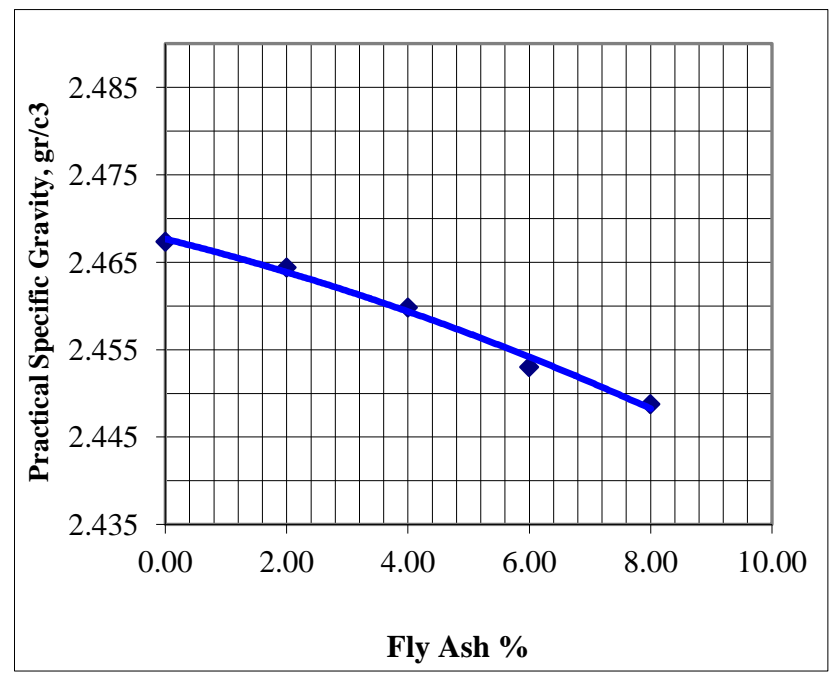

Figure 5. Bulk density result of FA

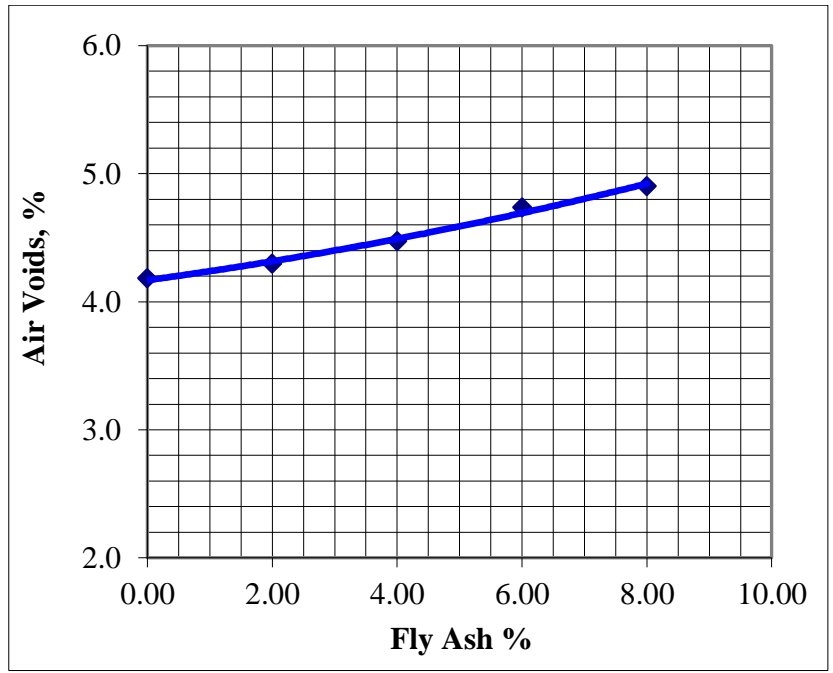

Figure 6. Air void result of FA

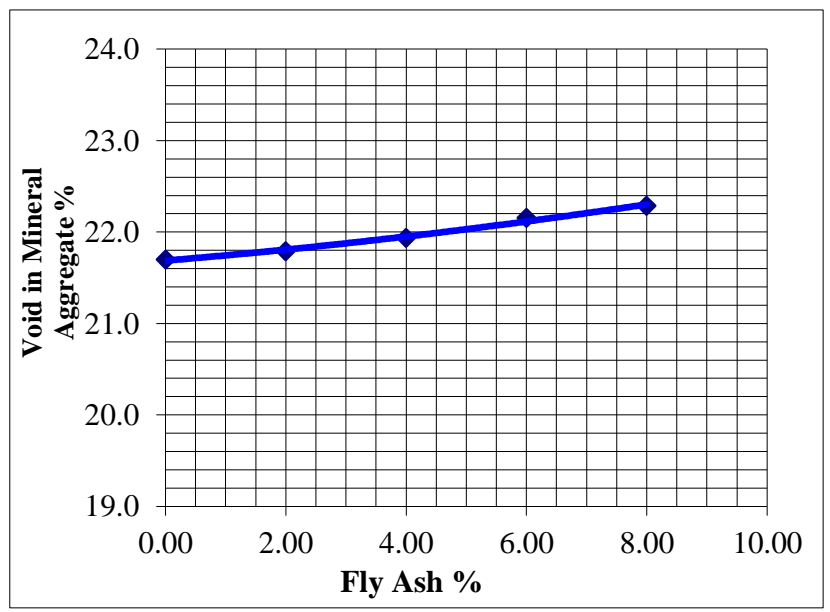

Figure 7. VFB result of FA

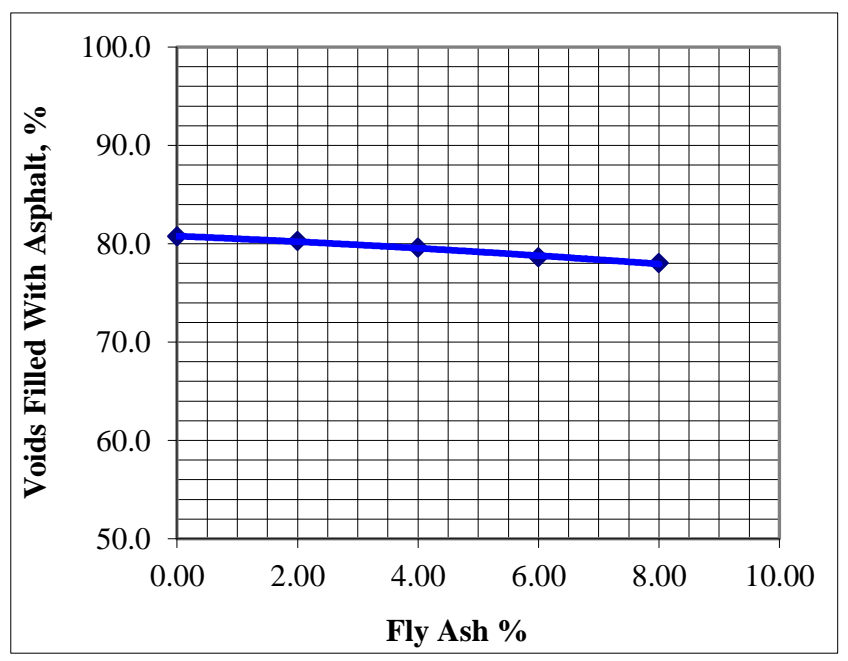

Figure 8. VMA result of FA 


\section{Microstructural image}

Figure 9 showed the microstructural image of the fly ash modified asphalt concrete. From the image, it was observed that, the mixture of asphalt and fly ash shows a homogenous phase with proper distribution of fly ash in the asphalt. The asphalt modified with fly ash demonstrated crack-mitigating behaviour of the spherical fly ash particle incorporated into the bitumen matrix as stated by previous researchers (Ramme et al., 2016; Bendapudi and Saha 2011), in their findings. The Fly ash modified mixture has the best homogeneous distribution of the asphalt membrane along with the hydration product material. The dense structure between mixing components was as a result of low air void content which was responsible for the improved properties that measure up to the acceptable standards.
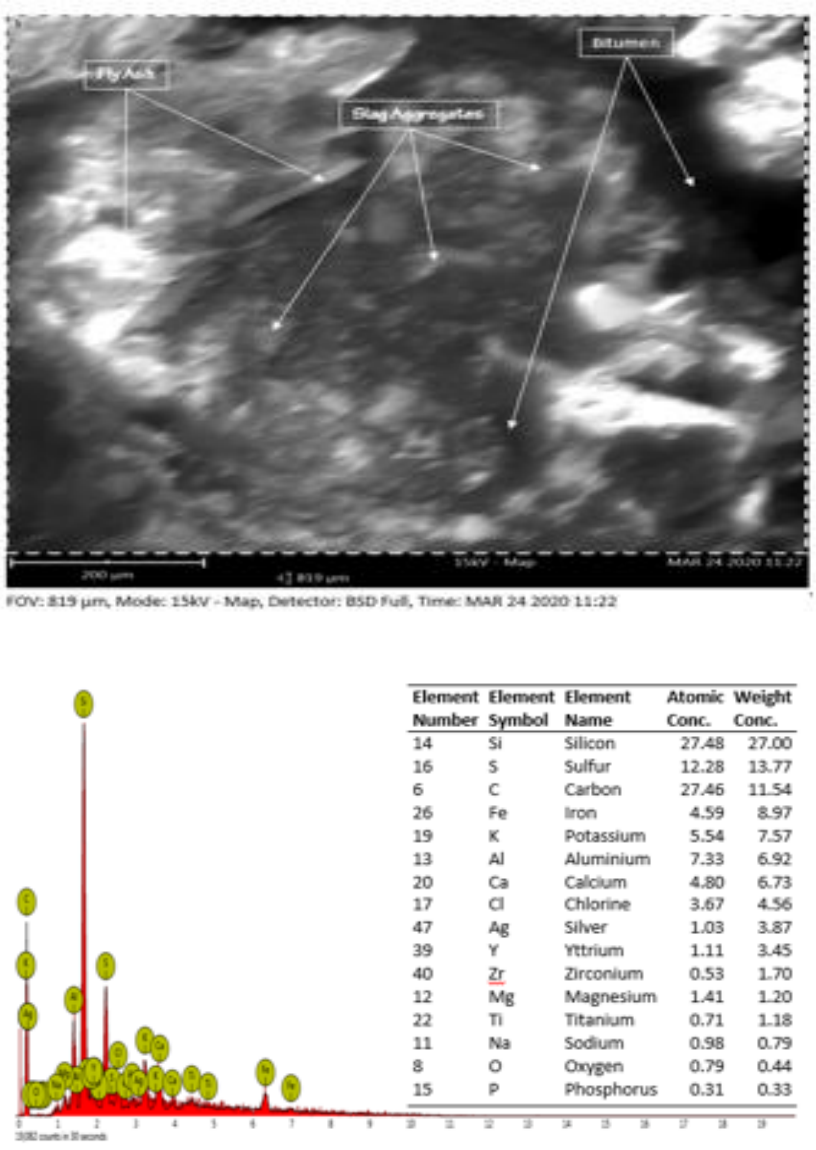

Figure 9. SEM Image of fly ash modified asphalt

\section{CONCLUSIONS}

The results of the investigation have revealed that fly ash can be acceptably used as replacement for stone dust in asphalt concrete. The study showed that marshal stability optimum value of $8.22 \mathrm{KN}$ obtained from $8 \%$ replacement with fly ash is suitable for heavy traffic while 2 to $6 \%$ fly ash modified asphalt concrete within the range of 7.39 to $7.90 \mathrm{KN}$ were adequate for medium traffic in accordance with criteria for the marshal mix design method provided by the Asphalt Institute. Also, the flow result from $2 \%$ to $8 \%$ with values $3.7,3.5,3.3$ and $3.0 \mathrm{~mm}$ conformed to Nigeria general specification for road and bridge which stated that maximum of $4 \mathrm{~mm}$ to minimum of $2 \mathrm{~mm}$ is the acceptable range for wearing course in production of asphalt concrete. Other marshal properties such air void, void in mineral aggregate and void filled with bitumen satisfied the Nigeria general specification for road and bridges. Hence, the use of fly ash as partial replacement for filler will reduce the demand for conventional material and cost of pavement construction.

\section{Conflict of interest statement}

There is no conflict of interest with any third party.

\section{REFERENCE}

Hossain A, Khan T, Ahmed J and Ashikuzzaman (2018). Influence of Fly Ash as Mineral filler in bituminous mix design. Journal of Trends in Civil Engineering and its Architecture. 3(2): 1-6. Google Scholar , http://doi.org/10.32474/tceia.2018.03.000156

Adil A and Saadoon E (2019). The use of cement production waste to improve the properties of hot mix asphalt concrete. Jordan Journal of Civil Engineering, 13(3): 394-404. Google Scholar

Kumar A and Kumar Chhotu A (2014). Experimental investigation of bituminous mixes using Fly ash as filler material, journal of civil engineering and environmental technology, 1(6): 4-6. Google Scholar

ASTM (2005). Standard test method of water in petroleum product and bituminous materials by distillation. American Society of Testing and Materials international West conshohochen.

ASTM (2006). Standard test method for marshal and flow of bituminous mixtures. American Society of Testing and Materials international West conshohochen.

ASTM (2010). Standard test method for kinematic viscosity of Asphalt (Bituminous). American Society of Testing and Materials international West conshohochen.

ASTM (2012). Standard test method for density, relative density (specific gravity) and absorption of coarse aggregate. American Society of Testing and Materials international West conshohochen.

ASTM (2013). Standard Guide for Elemental Analysis by wavelength dispersive x-ray fluorescence Spectrometry. American Society of Testing and Materials international West conshohochen. 
ASTM (2013). Standard test method for penetration of bituminous material. American Society of Testing and Materials international West conshohochen.

ASTM (2014). Standard test method for softening point of bitumen (ring and ball Apparatus). American Society of Testing and Materials international West conshohochen.

ASTM (2016). Standard test method for flash and fire point by Cleveland open cup tester.American Society of Testing and Materials international West conshohochen.

ASTM (2017). Standard test method for ductility of asphalt materials. American Society of Testing and Materials international West conshohochen.

ASTM (2017). Standard test method for particle distribution (Gradation) of fine-grained fillers using sedimentation (Hydrometers) Analysis. American Society of Testing and Materials international West conshohochen.

ASTM. (2019). Standard test method for determination of relative $x$-ray diffraction intensities of faujasite-type zeolites-containing material. American Society of Testing and Materials international West conshohochen.

Asphalt Institute (1997). Criteria for Marshal Mixture Design method.

Bandapudi SC and Saha P (2011). Contribution of fly ash to the properties of mortar and concrete. International journal of earth sciences and engineering, 4(6): 974-5904. Google $\underline{\text { Scholar }}$

EPA (2005). Using coal ash in highway construction. A guide to benefits and impacts. EPA-530-K-05-002, United States Environmental Protection Agency, USA., pp: 1-41. https://doi.org/10.3923/jas.2016.526.533, Google Scholar

FGN (1997). Government of the Federal Republic of Nigeria, General Specifications (Roads and Bridges), Volume II, 1997. Google Scholar

Goodarzi F. (2006). Characteristics and composition of fly ash from Canadian coal-fired power plants. Fuel. 85(1011):1418-27. https://doi.org/10.1016/j.fuel.2005.11.022 , Google Scholar

Ismail KN, Hussin K and Mohd SI (2007). Physical Chemical, and Mineralogical Properties of Fly Ash, Journal of Nuclear and Related Technology, 4(2), 34-51. Google Scholar

Ademola JA, Onyema UC. (2014). Assessment of natural radionuclides in fly ash produced at Orji River thermal
Power Station, Nigeria and the associated radiological impact. Natural Science. 6(10): 752-759. Google Scholar, http://dx.doi.org/10.4236/ns.2014.610075

Johnson J (2009). The foul side of clean coal: As power plants face new air pollution controls, ASH PILES and their environmental threats are poised to grow. Chemical and Engineering News. 87(8): 44-47. Google Scholar, https://doi.org/10.1021/cen-v087n008.p044

MalhotraVM (2002). Sustainable Development and concrete technology, ACI concrete inter, 24 (7), U.S.A, May, 22, Google Scholar

Ramme WB, Art C, Ahmed F, and Konstaintin S (2016). Fly ash -An important ingredient for use in hot-mix asphalt concrete. fourth international conference on sustainable construction material and technologies, department of civil engineering, college of engineering, temple university, north $12^{\text {th }}$ st Philadelphia, Pennsylvania, USA Google Scholar

Sarsam SI, and Lamy AK (2015). Fatigue life assessment of modified asphalt concrete. International Journal Resource knowledge 2(3), 30-41, Google Scholar

Sharma V, Chandra S and ChoudharyR (2010). Characterization of Fly Ash Bituminous concrete Mixes. Journal of Materials in Civil Engineering. ASCE 1209, https://doi.org/10.1061/(ASCE)MT.1943-5533.0000125 Google Scholar

Sobolev K, Vivian IF, Saha R, Wasiuddin NM, Saltibus NE. (2014). The effect of fly ash on the rheological properties of bituminous materials. Fuel.116: 471-477. Google Scholar, https://doi.org/10.1016/j.fuel.2013.07.123

Tapkin S (2008). Mechanical evaluation of asphalt-aggregate mixtures prepared with fly ash as a filler replacement. Canadian Journal of Civil Engineering. 35(1): 27-40. Google Scholar https://doi.org/10.1139/L07-082

Hashimoto T and Torii K. (2013). The development of highly durable concrete using classified fine fly ash in Hokuriku district. Journal of Advanced Concrete Technology. 11(11): 312-21. Google Scholar, https://doi.org/10.3151/jact.11.312

Vučinić DR, Miljanović IM, Rosić AA, Lazić P. (2003). Effect of $\mathrm{Na} 2 \mathrm{O} / \mathrm{SiO} 2$ mole ratio on the crystal type of zeolite synthesized from coal fly ash. Journal of the Serbian Chemical Society. 68(6): 471-8. Google Scholar, https://doi.org/10.2298/JSC0306471V 